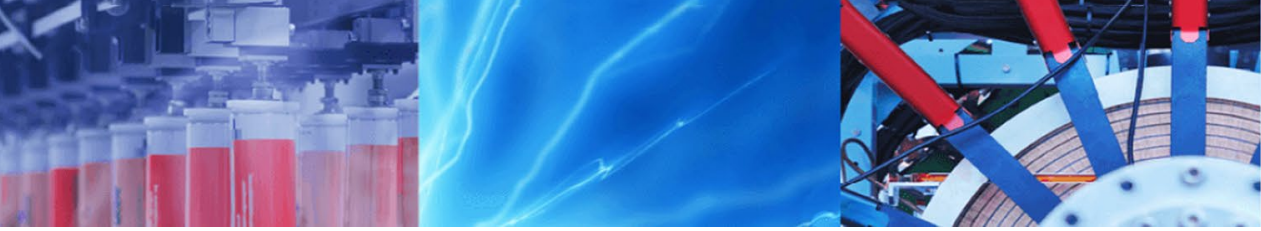

Research Article

\title{
Electrical resistivity mapping as a tool for post-reclamation assessment of subsurface condition at a sand-filled site in Lagos, southwest Nigeria
}

\author{
O. B. Olatinsu' ${ }^{1} \cdot$ K. F. Oyedele ${ }^{2} \cdot$ A. A. Ige-Adeyeye ${ }^{3}$
}

(c) Springer Nature Switzerland AG 2018

\begin{abstract}
The occurrence of collapsible and unstable subsurface materials (clay, silt, peats etc.) in alluvial deposits and other soil deposits throughout the world and the difficulties with building on them have long been recognized. Accordingly inclusive site investigation of subsurface condition is important for construction of engineering structures and buildings on land reclaimed from wetland such as marsh or swamp with soft compressible clays and peat materials. Peatlands common in most coastal areas of Lagos, Nigeria are characteristic waterlogged locations. These areas characterized by low human and economic activities in the past are now considered for building residential houses due to the surging population of the metropolis. Problem usually arises when there is uneven soil settlement which might results in disastrous collapse of structures. This study presents a subsurface geophysical mapping of a site reclaimed by sand filling in Victoria Island, Lagos, using integrated electrical resistivity techniques. The geoelectric data acquired through vertical electrical sounding (VES) and electrical resistivity imaging (ERI) techniques were processed and interpreted to provide a detailed characterization of the subsoil profile and soil parameters of the study area. VES technique employed Schlumberger configuration because of its obvious deeper current penetration, while for ERI, a combination of Werner, dipole-dipole and pole-dipole were utilized. Results from the two procedures show a maximum of four geoelectric strata, with the second and third layers consisting either sandy clay $(50 \Omega \mathrm{m}<\rho<140 \Omega \mathrm{m})$ or peat/clay $(\rho<50 \Omega \mathrm{m})$. These middle layers are sandwiched between the topsoil and the last layer (composed mainly of sand, $\rho>140 \Omega \mathrm{m}$ ). Due to the lateral discontinuous and inhomogeneous nature of these sandwiched layers of high compressibility and low shear strength, the possibility of occurrence of subsidence and differential settlement is high. This might result in minor or major failure in building and engineering structures built on such soils. Sand medium encountered at shallow depth of about 0.6-0.9 m, beneath VES 7, 8, 14 and 19, could have been a suitable layer for foundation of buildings and structures except that it is directly underlain by peat/clay. Other locations with competent sand layers for which deep foundation might be required lie at depth within 9.5-30.8 m. Thus, this study has revealed both the lateral and vertical variation with depth of the subsurface strata within the study area. This would assist local structural engineers and builders in designing appropriate and adequate foundation of structures in this area.
\end{abstract}

Keywords Reclamation $\cdot$ Sand $\cdot$ Peat $\cdot$ Resistivity $\cdot$ Subsurface $\cdot$ Mapping $\cdot$ Assessment

\footnotetext{
$\triangle$ O. B. Olatinsu, oolatinsu@unilag.edu.ng| ${ }^{1}$ Department of Physics, Faculty of Science, University of Lagos, Akoka, Lagos, Nigeria. ${ }^{2}$ Department of Geosciences, Faculty of Science, University of Lagos, Akoka, Lagos, Nigeria. ${ }^{3}$ Department of Physical Science, School of Pure and Applied Sciences, Lagos State Polytechnic, Ikorodu, Lagos, Nigeria.
} 


\section{Introduction}

Subsurface conditions in coastal areas and wetlands are very complex and of high degree of inhomogeneity. Out of the 356, 861 ha of Lagos land mass, 75, 755 ha are wetland [1]. Peat is a characteristic organic soil prevalent in most coastal areas of Lagos [2-6]. Organic soils store huge amounts of carbon as organic layers, which consist of dead, incompletely decomposed plant material that has accumulated over time in waterlogged environments. Furthermore, organic soil exhibit problematic properties such as high compressibility and low shear strength; these properties may cause differential settlement or failure in structures built on such soils [7].

In a bid to meet the high residential needs of its surging population, sand filling of wetlands close to the various lagoons in Lagos has become very popular in recent times among builders and estate developers. What is often ignored in most cases is the need for proper and adequate subsurface characterization before the commencement of the construction of buildings. This is one major contributing factor to the increasing incidents of building collapse in some areas within the metropolis.

The success of any coastal land reclamation project is highly dependent on sound planning and design practices, which generally include geophysical, geotechnical, engineering and some other non-engineering aspects. Some critical issues for consideration include general landforms, flooding, soil types for load-bearing capacity, water table level, presence of expansible and compressible clays and peats etc. In most reclamation projects handled by professionals, much consideration is usually given to the pre-reclamation geotechnical and geophysical engineering investigations in order to gather information on the nature, competence and configuration of subsurface strata $[8,9]$. However, to ensure overall success post-reclamation investigation and monitoring are also essential to verify the extent of settlement and to ascertain that the required degree of consolidation is achieved $[10,11]$. Despite the fact that some concern bordering on the socio-economic, environmental and marine ecological impacts have always been connected with land reclamation projects [12-15], it is however evident that globally, the overall economic and social benefits seem to far outweigh these associated problems. Most land reclamation projects are as much for coastal protection as for providing more land in geographically constrained and densely populated coastal areas. Indeed the socio-economic benefits of reclamation works are a strategic instrument for wetland/swamp and coastal development since land reclamation offers the possibility to implement spatial plans within congested coastline cities [16].
In subsurface investigation, geophysical surveying techniques provide a toolbox of rapid, discrete and cost effective methods for the location and identification of subsurface geological features. The various geophysical methods are designed to exploit one or more of the physical properties of a target feature that is in contrast with its host environment, e.g., the resistivity of salt intruded region in contrast to the high resistivity nature of surrounding material [17-19]. It is also recognized that careful examination of the likely physical characteristics of the target (size, depth and properties) is required to enable reliable assessment of whether it is detectable or not [20]. Geophysical methods have several important advantages, compared with conventional geotechnical field investigation methods which have limitations in terms of spread, coverage and the sky-high cost it entails [9, 21-31]. Typically, geophysical survey can explore relatively large soil volumes, with the potentials to delineate material properties, material boundaries as well as variations in space and time. Many of the methods have the additional advantage of being non-destructive. In most cases, it is sufficient to place sensors such as electrodes, geophones etc., on the ground surface (non-intrusive testing) to detect responses from natural or artificially generated signals in the earth's subsurface [32]. Electrical properties are among the most useful geophysical parameters in characterizing earth materials by virtue of the cost-effectiveness and simplicity in field implementation of most electrical survey methods. Variations in electrical resistivity (or conversely, conductivity) typically correlate with variations in lithology, water saturation, fluid conductivity, porosity and permeability [20]. In addition, geoelectric survey is an established technique employed in engineering site works to delineate competent geological zones in the subsurface. Its main advantage is in the determination of depth to competent layer across proposed sites as against conventional geotechnical test which is a point test [33]. This present work is focused on a post-reclamation investigation of a sand-filled site at Oniru Park, off Lekki-Epe expressway, Victoria Island, Lagos, Nigeria. The primary aim is to delineate and map out locations underlain by residual incompetent and compressible peat/clay strata in order to provide valuable pre-construction guides that will indeed assist in preventing the occurrence of differential settlement and subsidence. The objectives of this study are to use vertical electrical sounding (VES) technique and 2-D resistivity imaging to ascertain the appropriateness of the sand-filled exercise carried out on the expanse of land and to map out competent zones at the reclaimed site for foundation of engineering structures and buildings. 


\section{Geoelectric methods in site characterization and subsurface investigation}

Several studies have proven that in any engineering projects such as buildings, dams, highway, and bridges, the greatest risk lies in the uncertainties connected with subsurface conditions $[22,27,29,34-36]$. The risks are significantly increased with inadequate site investigations resulting in unpredictable construction costs and programming. Electrical resistivity is considered to be a suitable technique in geotechnical site characterization and environmental studies due to economic factors i.e. reduced cost of investigation and efficiency in terms of speed and reliability [28, 37-39]. Several workers have established the use of electrical resistivity techniques as a very effective and practicable geophysical tool in geotechnical and environmental investigation of the condition of subsurface earth materials. A water-borne streaming electrical resistivity survey was conducted in the Panama Canal to discern geotechnical properties in support of Canal expansion [24]. The comparison of electrical resistivity to rock hardness for co-located measurements showed that the resistivity data correlated with certain lithological clusters. These clusters of resistivity were then used to convert the calculated resistivity to a spatially continuous rock hardness attributes. Results from a study conducted in Garchy, France has given credence to the fact that electrical resistivity tomography (ERT) is a relevant method to determine clay (a low-strength soil) cover in a subsurface context [22]. This study also shows that inverted resistivity values obtained from 1-D soundings enhanced the discrimination of the different formations. The combination of geophysical data and geotechnical measurements may greatly improve the quality of buildings under construction in civil engineering [23]. A case study was carried out at a vacant building site using combined dipole-dipole configuration for ERT and electromagnetic terrain conductivity (ETC). This investigation demonstrated that engineering geophysics can provide solutions for determining subsurface properties and that different techniques of prospecting are necessary for developing a reasonable model of the subsurface structure. The determination of soil strength using ERT is economic, fast and efficient in comparison to the direct in situ methods used to determine soil strength for civil engineering purposes [9]. This was shown in a study conducted at two sites proposed for thermal power plants in Uttar Pradesh in India, where ERT was used in conjunction

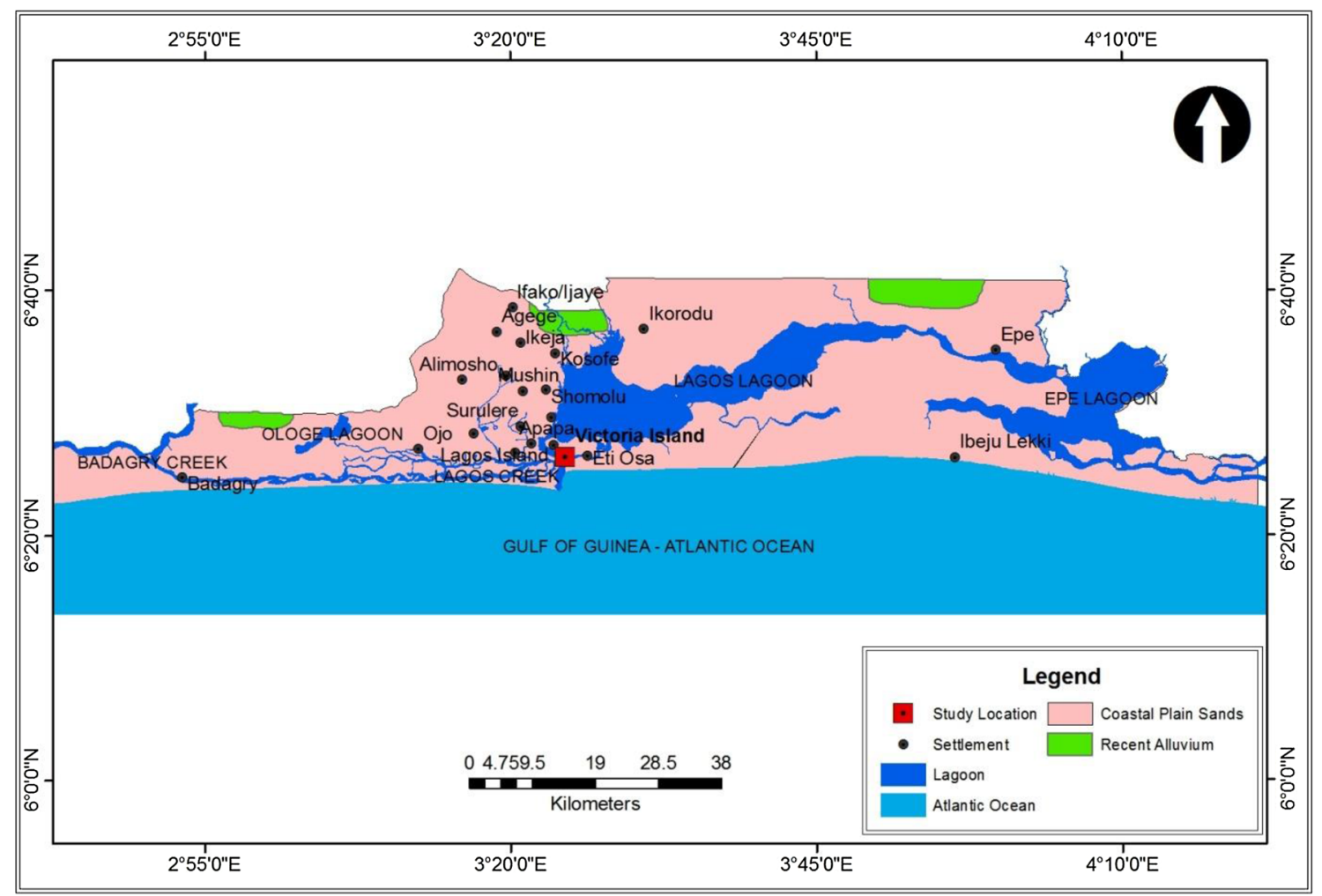

Fig. 1 Geological map of Lagos State showing the study area, Victoria Island 
with Standard Penetration Test (SPT) and Dynamic Cone Penetration Test (DCPT) for geotechnical investigations. A combination of electrical resistivity and seismic refraction tomography was employed to detect fracture zones in a well-known but logistically challenging area from a measurement perspective [31]. In this study, previously unknown sedimentary deposits with a significantly large thickness were detected by ERT in the otherwise unusually well-documented geological environment. In road engineering, the correct identification of soil conditions is essential since the substratum acts as a foundation for the pavement of the road. ERT carried out in the field during expressway construction has contributed to the identification of weak, low-strength organic soils such as peat and aggradated mud which are the main cause of deformations in road engineering structure in this study area [25]. Surveys using geoelectric method have allowed the characterization of the spatial variability of foundation structure for a bridge project in Warsaw environs, Poland [29]. Electrical resistivity imaging measurements using Schlumberger and gradient arrays were employed to obtain two-dimensional structure of soil resistivity variability. Resistivity image obtained with gradient array provided a much higher lateral resolution and a shallower depth of investigation than the Schlumberger array.

In foundation works for buildings and other engineering structures, peats and organic soils are a serious challenge because they are much weaker and more incompressible than the inorganic (mineral) soils [40]. Previous geological and geophysical survey conducted at some locations in coastal areas of Lagos State in Nigeria, have shown that most reclaimed land from water bodies or its equivalent (swamp, flood zones and abandon river channel) usually contain residual unstable and compressible geological materials such as peat, silt and clay [27, 41-44]. For this reason, it is important to employ non-invasive geophysical method such as electrical resistivity mapping in delineating these complex geological materials both at the pre-reclamation and post-reclamation stages in any engineering construction work. At a site near Zwierzyniec, north-east of Warszawa, central Poland, the locations of two peat horizons occurring within sandy deposits under a low resistivity clay layer were identified and characterized using ERT [26]. However, detailed geometry of the peat layer could not be determined due to the fact that the resistivity of peats was generalized with the resistivity of sand within which it occur. Electrical resistivity imaging was carried out to identify fen structure and peat properties in the Calowanie Fen area, Central Poland [30]. 2-D quasi-continuous images of the subsurface structure showing properties of peat and its substrate such as thickness and resistivity were obtained for the site. This work also demonstrated significant heterogeneity of peat in terms of moisture content, ash content and degree of

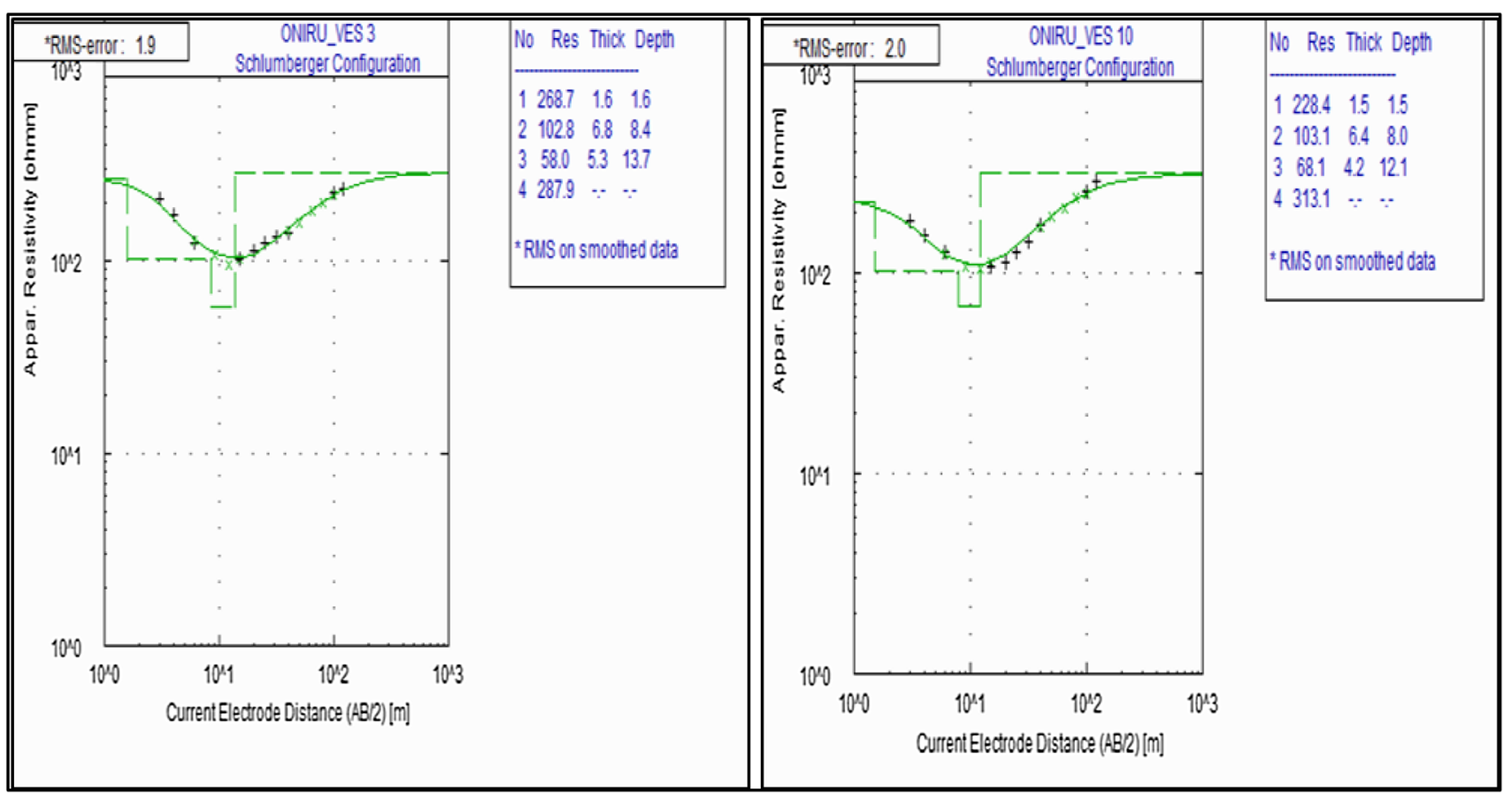

Fig. 2 Samples of results obtained from computer iterations with RMS error ranging from 1.3 to 2.5 
composition. Near-surface seismic refraction and electrical resistivity methods were conducted a location within Eti-Osa area of Lagos State, southwestern Nigeria [27]. The study aimed at characterizing the subsurface condition of a land reclaimed from water bodies, in order to determine the depth to the most competent layer for construction purposes. The third and fourth subsurface strata with good geotechnical properties were clearly delineated by the electrical resistivity method.

\section{Description and geology of study area}

Lagos State is located in the south-western part of the Nigerian Federation. On the north and east, it is bounded by Ogun State. In the west it shares boundaries with the Republic of Benin. Behind its southern borders lies the Atlantic Ocean. Lagos metropolis is the area of land around the only inlet of the sea into the extensive lagoon system—the Lagos harbor [45]. The islands in the area include Lagos Island, Victoria Island and Ikoyi as well as the Lekki peninsula. The site for this present study is situated in Victoria Island, a fast growing business district located in the south eastern part of the state. The study site falls within the defunct Maroko settlement (about $27,000 \mathrm{~m}^{2}$ ), a low-income and under developed slump area with shanties which was demolished over 20 years ago by the Lagos State government, because the area undermines the "megacity status" that the state is aiming to achieve. This major business hub lies between latitudes $6^{\circ} 27^{\prime} 12^{\prime \prime}$ and $6^{\circ} 27^{\prime} 30^{\prime \prime} \mathrm{N}$ and longitudes $3^{\circ} 27^{\prime}$ and $3^{\circ} 30^{\prime} \mathrm{E}$. As in many major cities in the world, limited land space in Lagos metropolis has engendered small and large reclamation projects for diverse uses such as housing, recreation, industrial estates since the period the city was the capital of Nigeria. High-rise commercial buildings and recreational facilities have been built recently on large reclaimed land. These land reclamations are sited near shore or just off-shore locations. A good example is the on-going Eko Atlantic City project that covers an expanse of land close to the Atlantic Ocean. This ambitious residential and business development project was proposed by the Lagos State government in an effort to protect Bar Beach in Victoria Island from the effects of severe coastal erosion, and to safeguard Victoria Island from the threat of flooding [46-48]. Much land has been reclaimed using hydraulically filled sand. In most reclamation works close to the

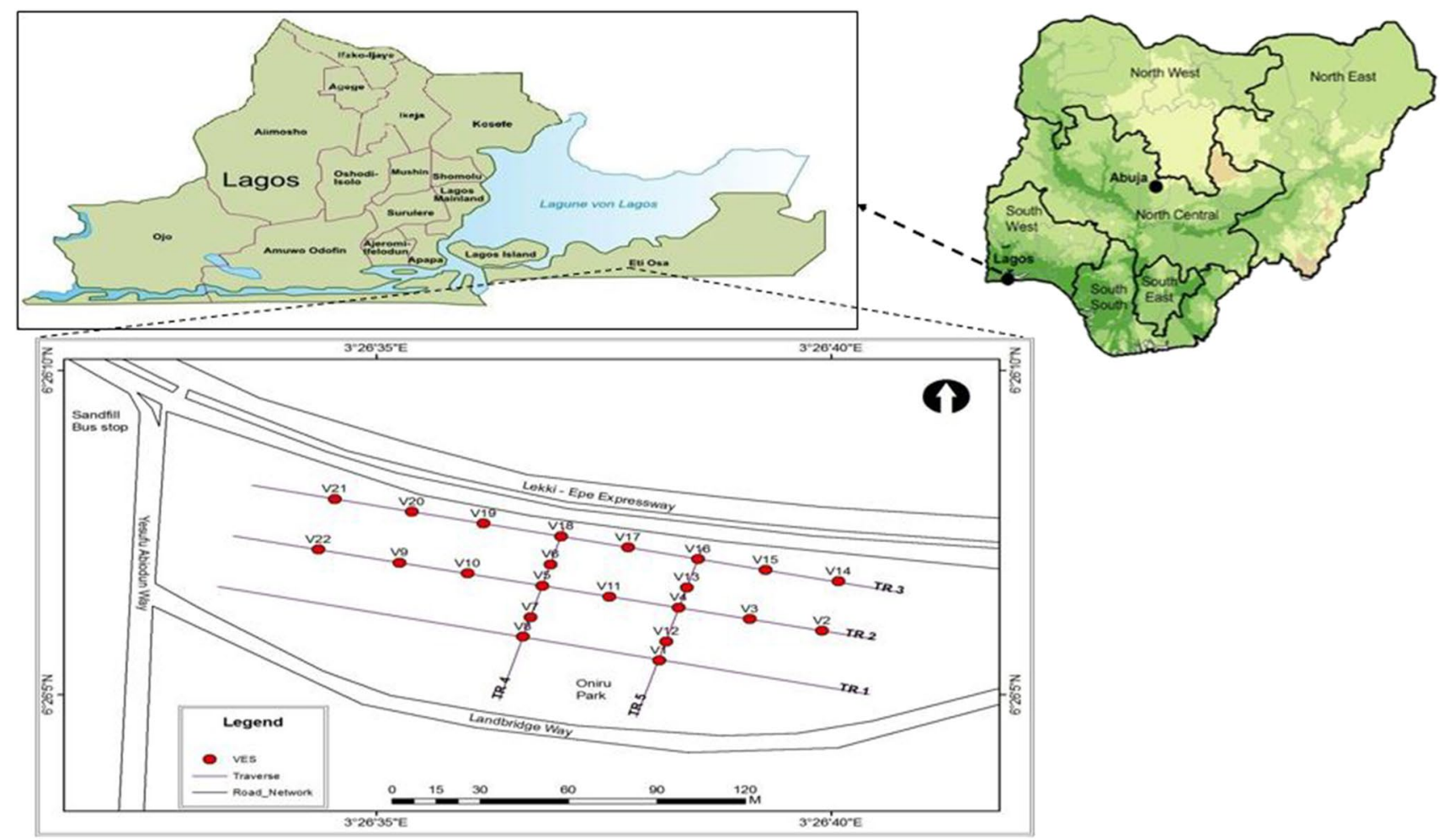

Fig. 3 Data acquisition map showing the 2-D traverses and the VES stations. Survey lines are arranged such that TR4 and TR5 are positioned across TR1, TR2 and TR3 
Lagos lagoons, unstable earth materials mainly peat and clay bodies are filled with granular soil such as sand and allowed to undergo considerable settlement over a period of time.

The surface geology of Lagos State is made up of the Benin Formation (Miocene to Recent) and Recent littoral alluvial deposits (Fig. 1). The Benin Formation consists mainly of yellowish (ferruginous) and white sand bodies [49]. It is friable, poorly sorted with intercalation of shale, clay lenses and sandy clay with lignite. The formation reaches a thickness of about $200 \mathrm{~m}$ elsewhere [50] and is overlain in many other places by considerable thickness of red materials composed of iron-stained regolith formed by weathering and ferruginization of rocks [51]. Lagos State is a zone of coastal creeks and lagoons which is entirely surrounded by the Lagos lagoon systems developed by barrier breaches associated with sand deposits $[52,53]$. Five geomorphological sub-units have been identified in the coastal landscape of Lagos State, which are: the abandoned beach ridge complex; the coastal creeks and lagoons; the swamp flats; the forested river flood plain and the active barrier beach complex [54]. The study area lies within the loose sediment ranging from silt, clay and fine to coarse grained sand usually referred to as the coastal plain sand (Fig. 1).

\section{Methods}

The electrical resistivity measurements for this study are the 1-D vertical electrical sounding (VES) and 2-D electrical resistivity imaging (ERI) techniques with the use of Ohmega resistivity meter unit and accessories (Allied Associates, UK). VES employs collinear arrays designed to output a one dimensional vertical apparent resistivity versus depth model of the subsurface at a specific observation point (Fig. 2). In this study, VES technique employing Schlumberger configuration was deployed to obtain field resistivity data. A series of potential difference $(\Delta V)$ were acquired at successively greater electrode spacing while maintaining a fixed central reference point. The injected current passes through progressively deeper layers at greater electrode spacing. The potential difference measurements are directly proportional to the changes in the deeper subsurface. Qualitative interpretation of VES data obtained was done through manual processing by plotting apparent resistivity values against half-electrode spacing to obtain the field curves $[55,56]$. Quantitative interpretation was achieved through computer iteration with the aid of WinResist software version $1.0[57,58]$. Samples of the iterated results are shown in Fig. 2. Apparent resistivity $\left(\rho_{a}\right)$ values generated were interpreted in
Fig. 4 Available borehole data from sand-filled sites from Oniru Estate (BH1 and $\mathrm{BH} 2)$, Lekki peninsula $(\mathrm{BH} 3)$ and Eti-Osa (BH4). BH5 is from a site that is not sand-filled in Ikoyi

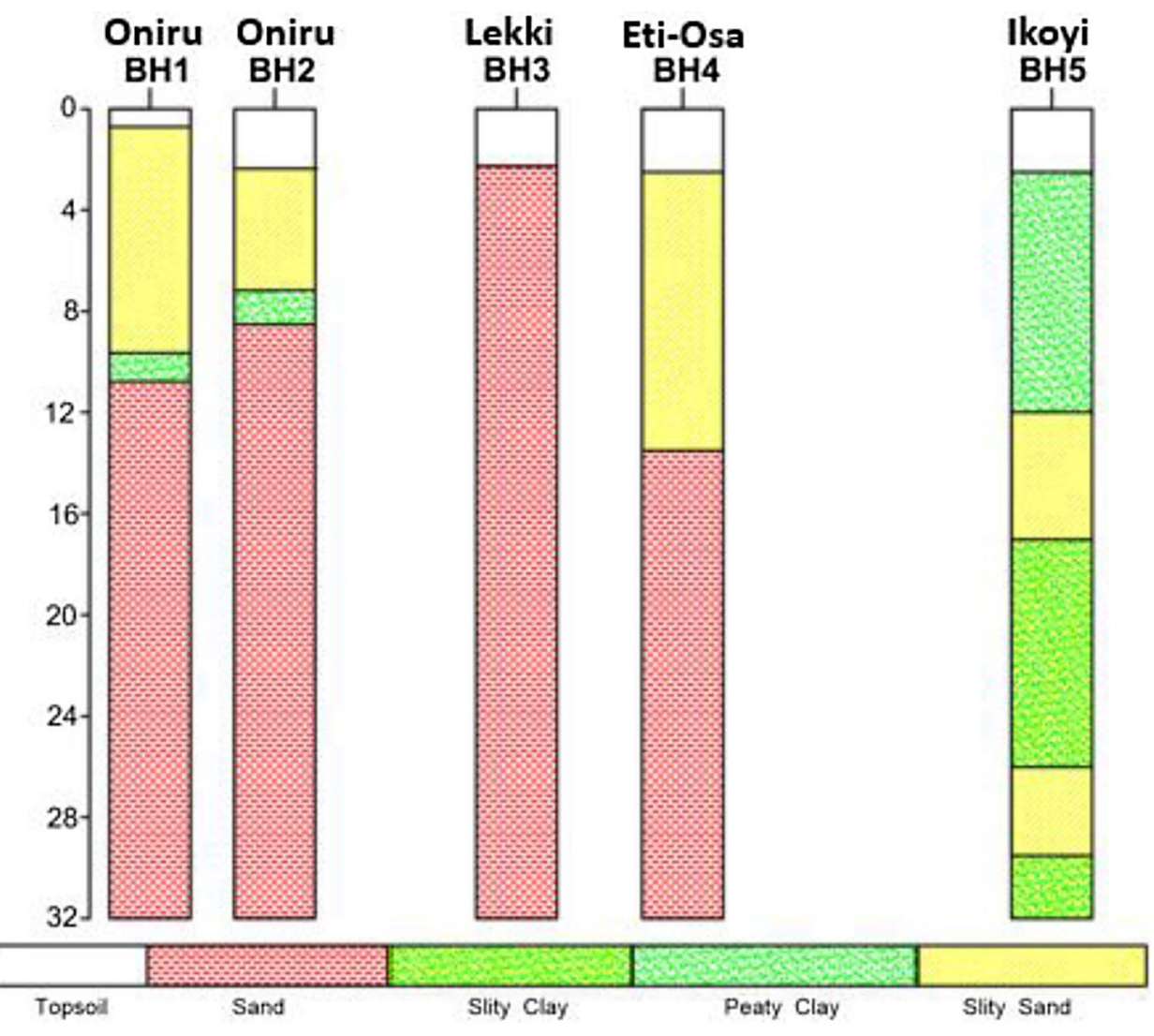


Table 1 Summary of VES results

\begin{tabular}{lllll}
\hline VES no. & Resistivity $(\Omega m)$ & Thickness $(\mathrm{m})$ & $\begin{array}{l}\text { Resistivity } \\
\text { curve type }\end{array}$ & Lithological description \\
\hline 1 & & & & \\
2 & $808.6 / 74.6 / 23.9 / 557.1$ & $0.9 / 2.8 / 4.8 / \infty$ & $\mathrm{QH}$ & Topsoil/sandy clay/peat/sand \\
3 & $325.1 / 59.4 / 35.1 / 121.6$ & $0.8 / 3.7 / 18.3 / \infty$ & $\mathrm{QH}$ & Topsoil/sandy clay/peat/sandy clay \\
4 & $402.6 / 88.0 / 29.8 / 613.6$ & $1.0 / 4.5 / 9.6 / \infty$ & $\mathrm{QH}$ & Topsoil/sandy clay/peat/sand \\
5 & $494.9 / 109.1 / 42.7 / 228.2$ & $0.6 / 2.0 / 16.9 / \infty$ & $\mathrm{QH}$ & Topsoil/sandy clay/peat/sand \\
6 & $449.6 / 36.1 / 48.1 / 158.8$ & $0.8 / 3.9 / 38.6 / \infty$ & $\mathrm{HA}$ & Topsoil/peat/peat/sand \\
7 & $368.1 / 127.8 / 40.4 / 147.5$ & $0.9 / 2.4 / 20.4 / \infty$ & $\mathrm{QH}$ & Topsoil/sand/peat/sand \\
8 & $211.9 / 89.9 / 31.5 / 421.7$ & $0.8 / 3.2 / 2.1 / \infty$ & $\mathrm{QH}$ & Topsoil/sandy clay/peat/sand \\
9 & $953.5 / 108.6 / 52.9 / 274.2$ & $1.0 / 2.4 / 11.8 / \infty$ & $\mathrm{QH}$ & Topsoil/sandy clay/peat/sand \\
10 & $245.7 / 56.0 / 27.0 / 745.8$ & $1.2 / 4.1 / 8.0 / \infty$ & $\mathrm{HA}$ & Topsoil/peat/peat/sand \\
11 & $297.4 / 62.2 / 38.3 / 295.3$ & $1.0 / 2.9 / 15.1 / \infty$ & $\mathrm{QH}$ & Topsoil/peat/peat/sand \\
12 & $249.0 / 62.2 / 78.2 / 347.2$ & $1.2 / 10.2 / 11.4 / \infty$ & $\mathrm{HA}$ & Topsoil/sandy clay/sandy clay/sand \\
13 & $632.4 / 88.9 / 25.2 / 759.2$ & $0.6 / 1.9 / 9.5 / \infty$ & $\mathrm{QH}$ & Topsoil/sandy clay/peat/sand \\
14 & $828.3 / 184.5 / 67.7 / 317.4$ & $0.6 / 1.5 / 13.1 / \infty$ & $\mathrm{QH}$ & Topsoil/sand/sandy clay/sand \\
15 & $614.2 / 77.3 / 35.1 / 141.0$ & $0.6 / 4.0 / 18.6 / \infty$ & $\mathrm{QH}$ & Topsoil/sandy clay/peat/sand \\
16 & $332.2 / 60.3 / 117.7 / 290.0$ & $0.8 / 7.2 / 10.8 / \infty$ & $\mathrm{HA}$ & Topsoil/sandy clay/sand/sand \\
17 & $176.1 / 59.4 / 65.6 / 249.6$ & $0.9 / 8.4 / 16.2 / \infty$ & $\mathrm{HA}$ & Topsoil/sandy clay/sandy clay/sand \\
18 & $298.0 / 77.3 / 29.9 / 198.7$ & $1.6 / 3.3 / 14.8 / \infty$ & $\mathrm{QH}$ & Topsoil/sandy clay/peat/sand \\
19 & $1193.7 / 111.1 / 33.5 / 1502.6$ & $0.7 / 2.6 / 14.4 / \infty$ & $\mathrm{QH}$ & Topsoil/sand/peat/sand \\
20 & $538.8 / 42.4 / 76.5 / 251.8$ & $1.4 / 9.5 / 19.9 / \infty$ & $\mathrm{HA}$ & Topsoil/peat/sandy clay/sand \\
21 & $977.3 / 89.8 / 30.8 / 324.6$ & $1.2 / 3.8 / 6.6 / \infty$ & $\mathrm{QH}$ & Topsoil/sandy clay/peat/sand \\
22 & $685.2 / 82.4 / 52.9 / 301.4$ & $1.4 / 3.0 / 8.2 / \infty$ & $\mathrm{QH}$ & Topsoil/sandy clay/peat/sand \\
\hline & & & &
\end{tabular}

terms of resistivity, depths and thicknesses of subsurface strata $[18,59,60]$. Twenty two (22) stations (Fig. 3) were occupied along mainly three traverses (TR1, TR2 and TR3)

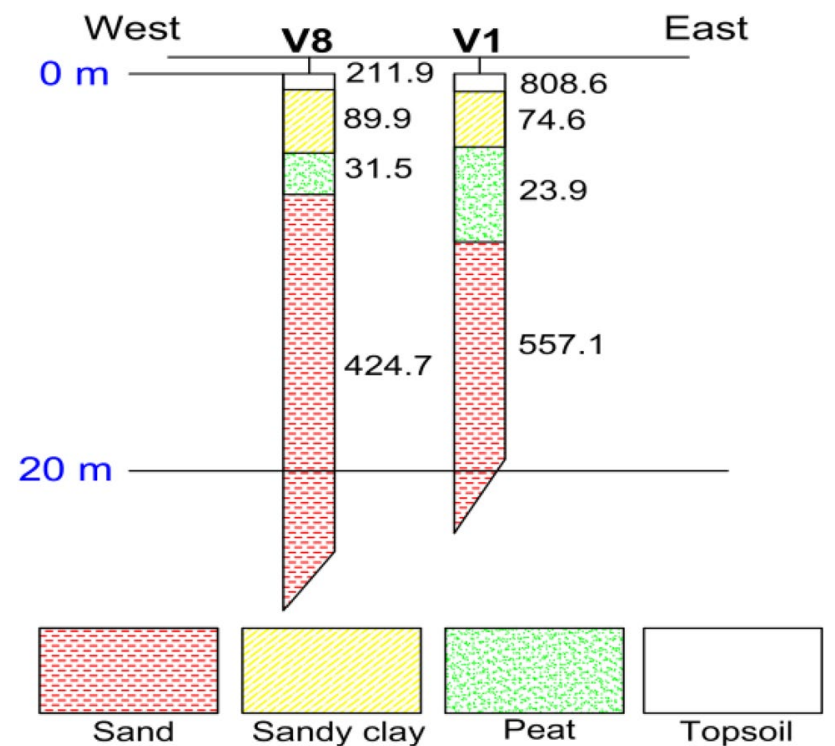

Fig. 5 Geoelectric cross-section along traverse TR1 with sounding stations V1 and V8. The depths to competent sand layer are $9.5 \mathrm{~m}$ and $6.1 \mathrm{~m}$ respectively with maximum inter electrode spacing of $240 \mathrm{~m}$. Traverses TR4 and TR5 consist of sounding points arranged across the first three traverses.

A total of seven (7) resistivity imaging arrays along three traverses were occupied over $200 \mathrm{~m}$ survey lines, with a line spacing of $10 \mathrm{~m}$ (Fig. 3). Acquisition of resistivity imaging data involved the deployment of in-line arrays of Werner (3), pole-dipole (2) and dipole-dipole (2) configurations respectively, due to spatial constraint and in an attempt to take advantage of the relative strength of these three commonly adopted arrays. Generally the depth of investigation depends on the electrode separation and geometry, with greater electrode separations yielding bulk resistivity measurements at greater depths [61-64]. 2-D data acquired was processed via complex combinations of current and potential electrode pairs to build up a pseudo cross-section of apparent resistivity beneath the survey lines. The modeled true interpreted subsurface resistivity image was then derived from finite-difference forward modeling using specialist software, DIPRO version 4.01 [65]. The interpreted resistivity models are usually presented as colour-scaled contour plots of changes in subsurface resistivity with depth. 
Fig. 6 Geoelectric crosssection along traverse TR2 consisting of sounding stations V2-V9 and V22. The depths to sand layer range from 11.6 to $22.8 \mathrm{~m}$

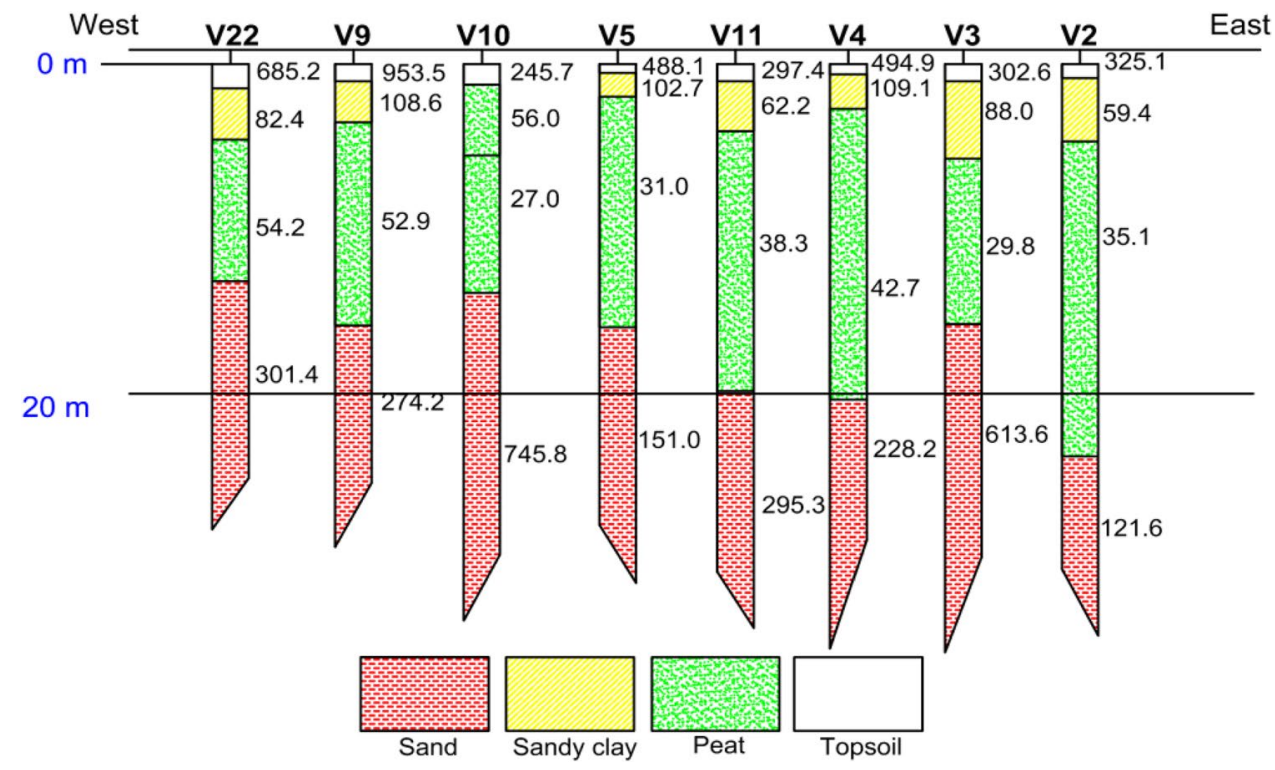

\section{Results and discussion}

\subsection{Vertical electrical sounding}

Apparent resistivity data are presented as sounding curves by plotting the apparent resistivity against half the current electrode separation $(A B / 2)$ on a logarithmic scale. Two main resistivity curve types, indicating subsurface sequence of resistive/moderately resistive/conductive/ resistive layers, are predominant in the study site viz: $\mathrm{QH}$ (79\%) and HA (21\%). These curve types essentially show that the study site was excavated to a considerable depth before sand-filling was carried out. Furthermore, measures to help constrain and aid the interpretation of the geophysical results by obtaining lithological information of boreholes from locations with similar geological environment to the study location (Fig. 4). Borehole logs $\mathrm{BH} 1$ and $\mathrm{BH} 2$ are from sand-filled sites within Oniru Estate while
Fig. 7 Geoelectric crosssection along traverse TR3 consisting of sounding stations V14-V21. The deeper sand layer is at a depth range from 11.6 to $30.8 \mathrm{~m}$

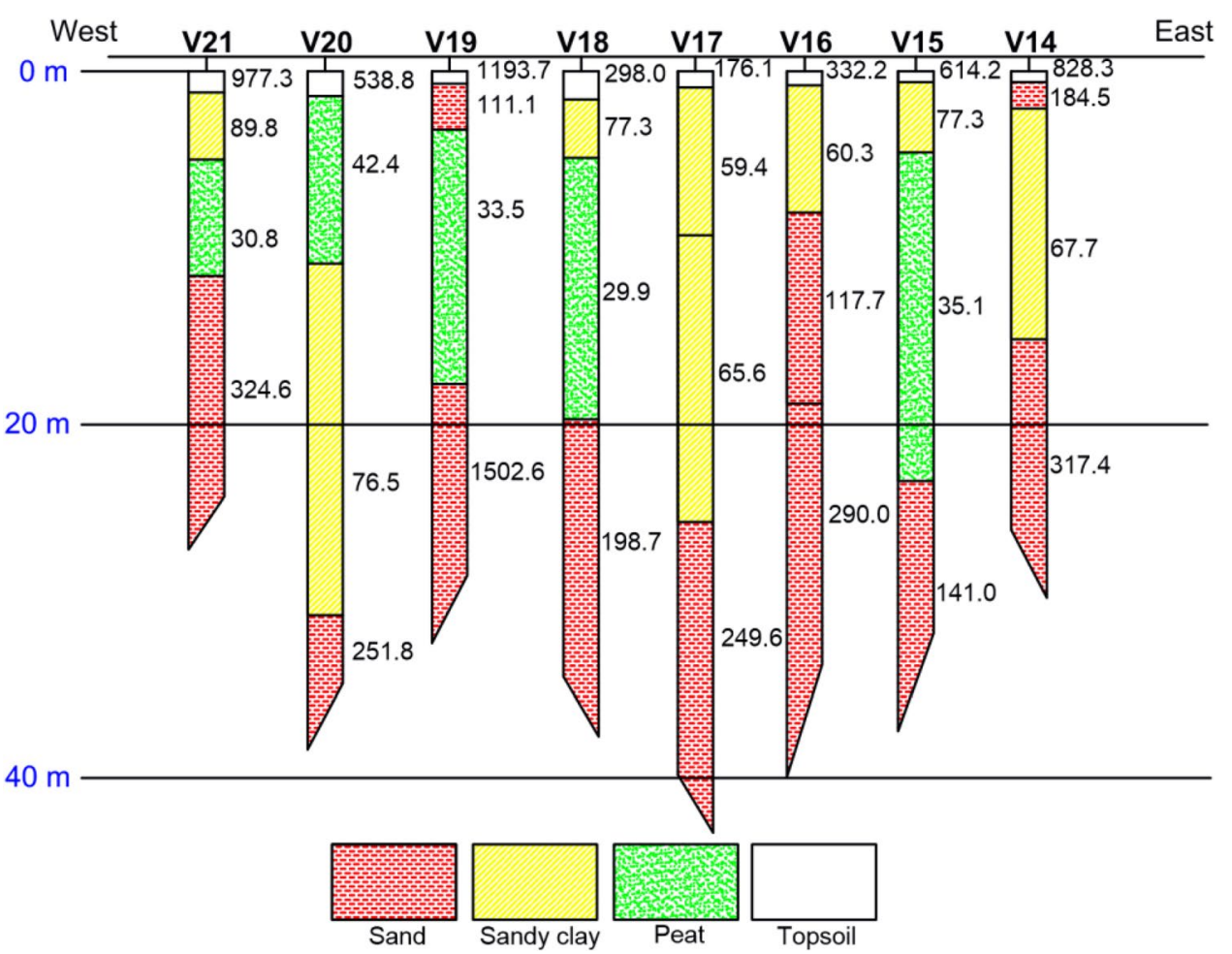




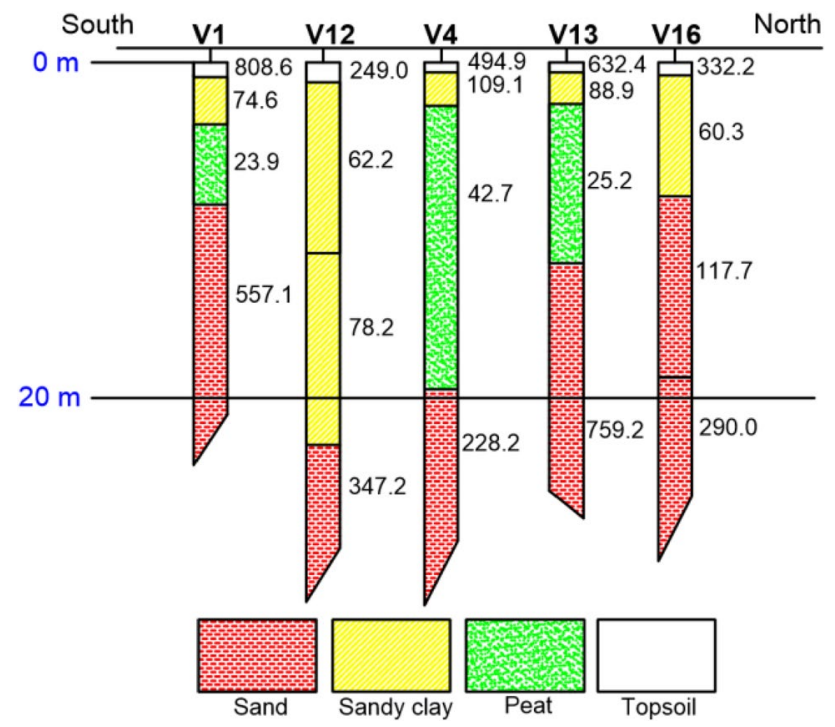

Fig. 8 Geoelectric cross-section along traverse TR5 (V1, V12, V4, V13 and V16) arranged across TR1, TR2 and TR3. Sand layer is encountered at a depth ranging from 9.5 to $22.8 \mathrm{~m}$

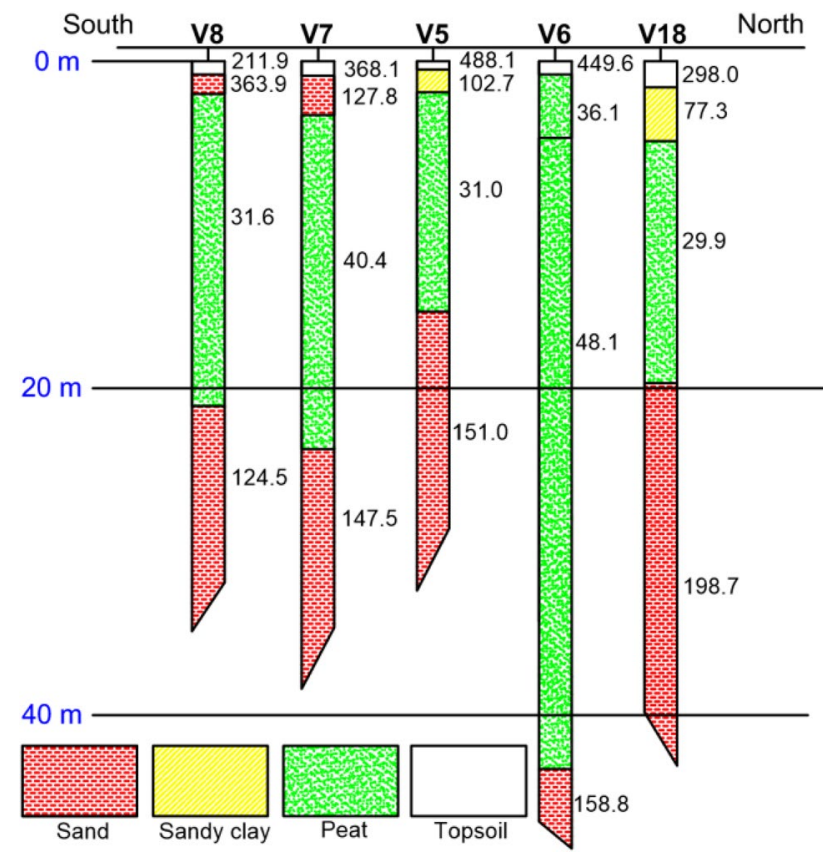

Fig. 9 Geoelectric cross-section along traverse TR4 (V8, V7, V5, V6 and V18) cutting across TR1, TR2 and TR3. The depths to competent sand layer range from 15.3 to $43.3 \mathrm{~m}$

$\mathrm{BH} 3$ and $\mathrm{BH} 4$ are from sand-filled sites at Lekki peninsula and Eti-Osa respectively. $\mathrm{BH} 5$ was obtained from a site at Ikoyi where sand-filling is yet to be carried out. It is clear that there are lithological differences between $\mathrm{BH} 1-4$ and
Table 2 Relationship between unconfined compressive strength and soil quality [67]

Compressive Quality of soil strength $(\mathrm{kPa})$

\begin{tabular}{ll}
\hline$<25$ & Vey soft \\
$25-50$ & Soil \\
$50-100$ & Medium \\
$100-200$ & Stiff \\
$200-380$ & Very stiff \\
$>380$ & Hard \\
\hline
\end{tabular}

Table 3 Typical values of smallstrain shear modulus [68]

\begin{tabular}{ll}
\hline $\begin{array}{l}\text { Small-strain } \\
\text { shear modulus } \\
(\mathrm{MPa})\end{array}$ & Type of soil \\
\hline $2.75-13.75$ & Soft clays \\
$6.90-34.80$ & Firm clays \\
$27.60-13.80$ & Silty sands \\
$69.00-345.00$ & $\begin{array}{l}\text { Dense } \\
\text { sands and } \\
\text { gravels }\end{array}$ \\
& g \\
\hline
\end{tabular}

BH5 evidence in the absence of compressible and soft subsurface materials such as silty clay and peaty clay formations in $\mathrm{BH} 1-4$. Also, the correlation between the logs and the VES sounding results forms the basis for the ranges of resistivity values in classifying the different lithology in the study area. Summary of interpreted geoelectric layers, thicknesses and inferred lithological units are presented in Table 1. Furthermore, for a quick view, the geoelectric cross-sections generated based on this correlation are presented in Figs. 5, 6, 7, 8 and 9. A maximum of four discontinuous geoelectric layers were delineated from the lithological interpretation of the VES models and these are topsoil, sandy clay (moderate shear strength and low compressibility), peat/clay (low shear strength and high compressibility) and sand (high shear strength and very low compressibility) [66]. Tables 2 and 3 also provide some guides to this classification. These two representations of the interpreted data show intercalations of subsurface layers in all the VES stations. Pockets of collapsible peat/clay medium with resistivity values less than $50 \Omega m$ at depth less than $1.5 \mathrm{~m}$ are observed in the entire survey area covered. However competent sand layers are encountered at depth of about $5 \mathrm{~m}$ and above at most of the locations.

\subsection{Electrical resistivity imaging}

Results from 2-D inversion of ERI resistivity data are presented as resistivity-depth structures (Figs. 10, 11, 12, $13,14,15,16)$. Acquisition of ERI data was conducted 


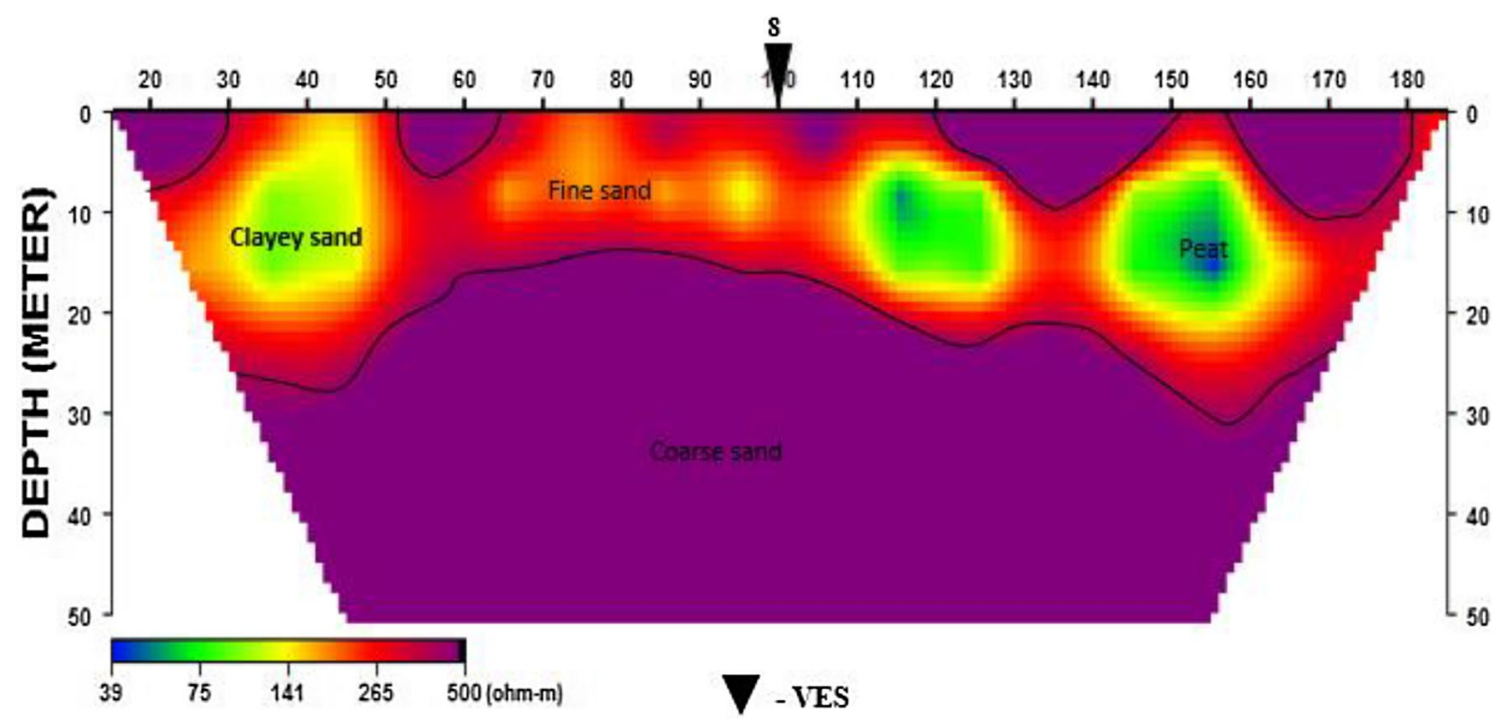

Fig. 10 Wenner 2-D resistivity structure along traverse one

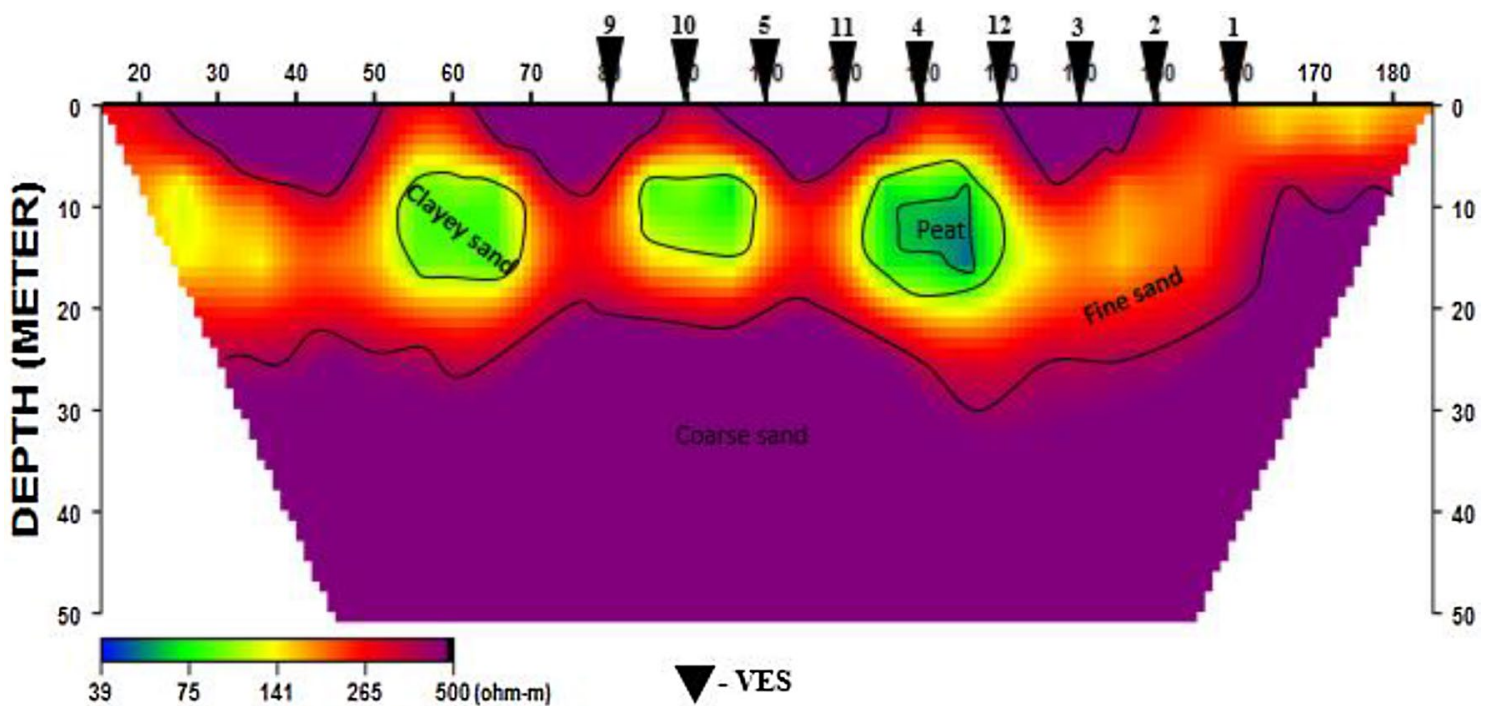

Fig. 11 Wenner 2-D resistivity structure along traverse two

on the same traverses outlined for the VES data acquisition. The VES results coupled with lithological data were incorporated into the interpretation of the ERI profiles to boost the level of confidence placed on using geophysical inversion to map subsurface geology at the study site. Subsurface resistivity distributions of the study site show some resemblance despite the fact that different electrode configurations were employed for data acquisition. These lateral and vertical resistivity variations reveal four distinct subsurface lithology in agreement with the result from the sounding data. The wide subsurface resistivity range $(39-500 \Omega \mathrm{m})$ depicts variation in soil matrix, grain size and water content of the subsurface materials. Low resistivity zones composed of clayey sand or clay/peat are interspersed within the middle layers which lie between the near surface layer and the deeper subsurface layer composed mainly of sand materials of moderate resistivity values. The thickness of the sandwiched compressible marshland clay/peat medium is less than $20 \mathrm{~m}$ along traverses TR2 and TR3 and more at the other two traverses. It is presumed that the clay/peat material is water-saturated with resistivity values below $50 \Omega \mathrm{m}$. This water-saturated condition coupled with the usual high percentage composition of decomposed organic matter, silt and humus soil suggests the high probability of occurrence of load sliding and as a consequence make such load mobile. 


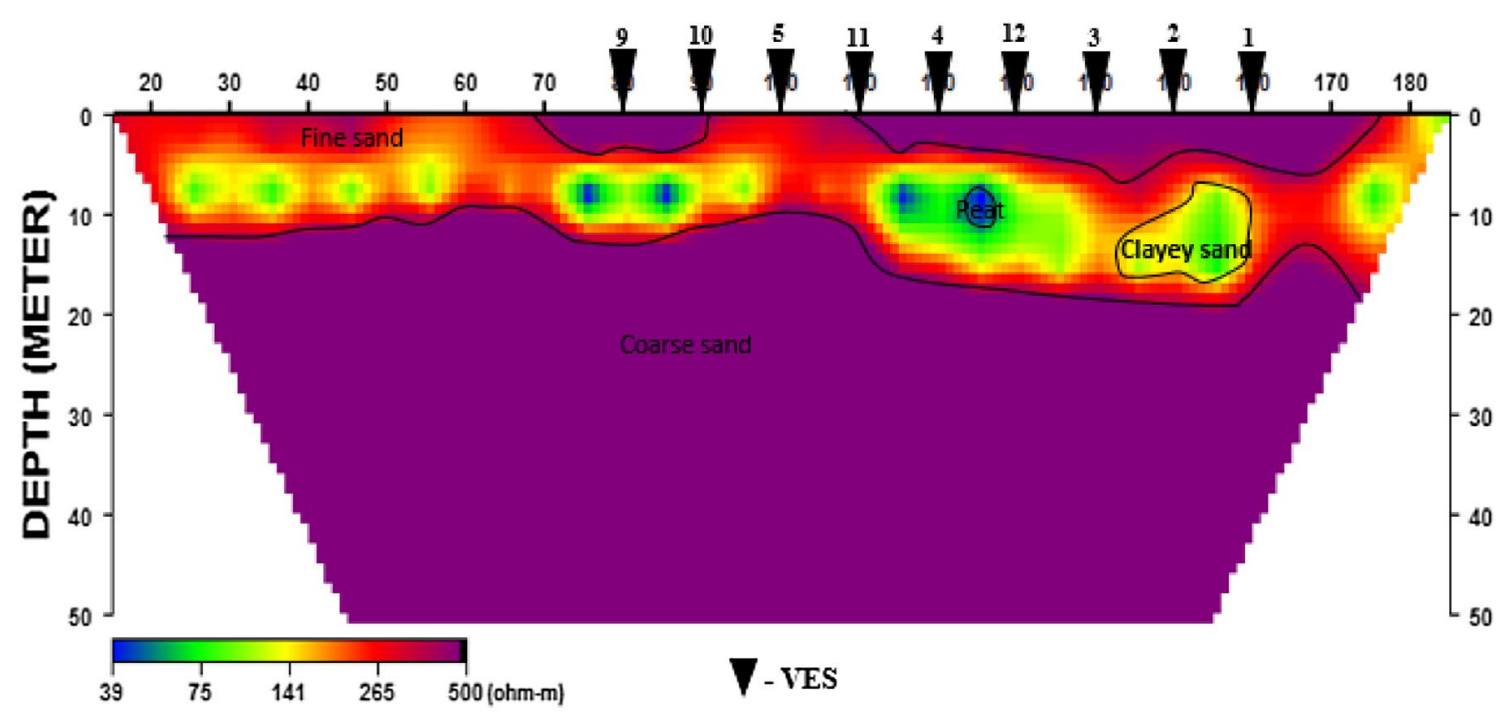

Fig. 12 Dipole-dipole 2-D resistivity structure along traverse two

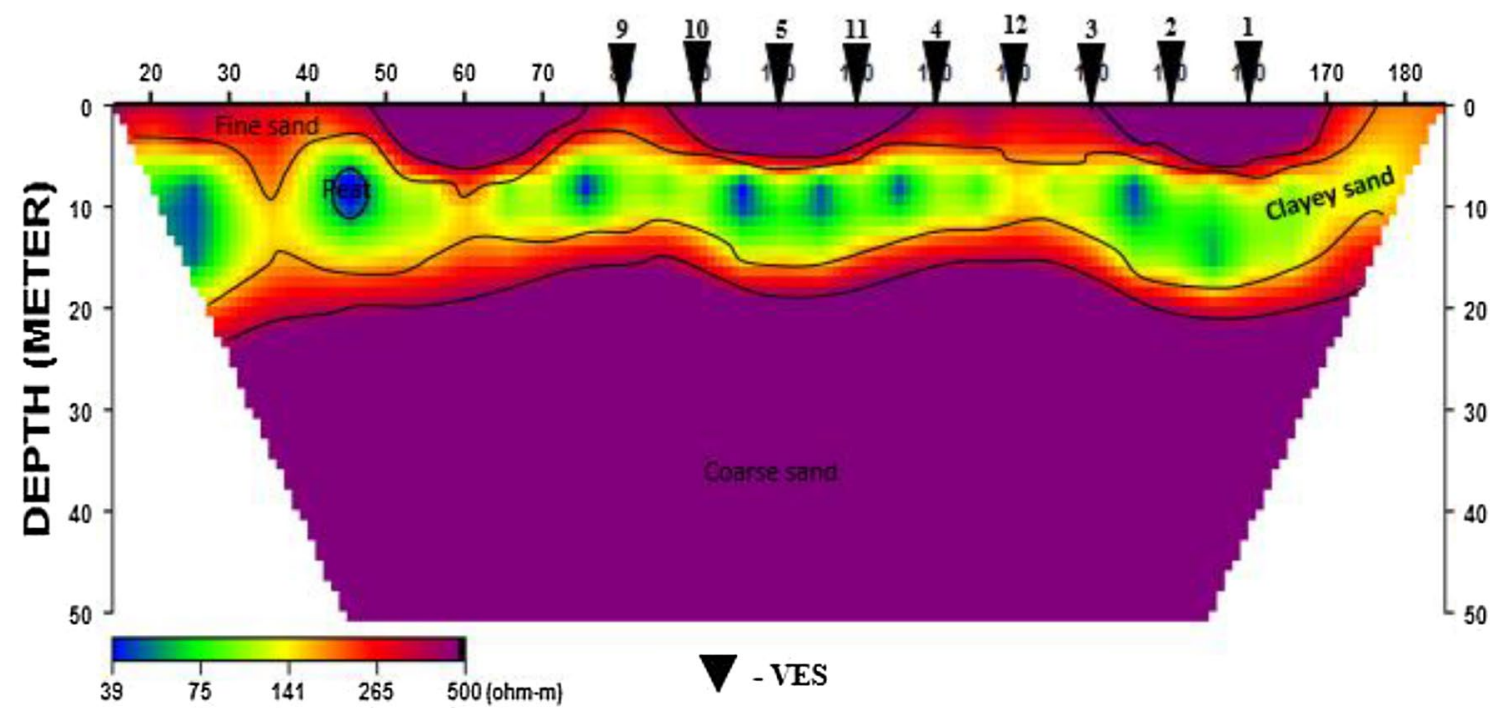

Fig. 13 Pole-dipole 2-D resistivity structure along traverse two

Furthermore, these earth materials predominant in wetland areas are a major cause of ground instability which could be a potential source of structural hazards in this study area. Hence shallow foundation is not encouraged for engineering structures of high or heavy buildings in this area.

\section{Conclusion}

Geophysical investigation to assess subsurface conditions and nature of surficial materials is an essential preconstruction tool in wetland environments.
Subsurface evaluation of the sand-filled site at Victoria Island, Lagos using electrical resistivity mapping techniques has revealed useful information typical of coastal areas in Lagos that would assist building professionals in the planning and design of engineering structures. The interpreted VES and 2-D resistivity imaging results show that the sand-filling conducted on the reclaimed site is presumed adequate to certain depth where sand medium is moderately spread across the covered area. Also thin layers of sand are revealed at shallow depth above sandy clay layers and in few location, pockets of discontinuous peat/clay medium were delineated. The direct implications of these findings 


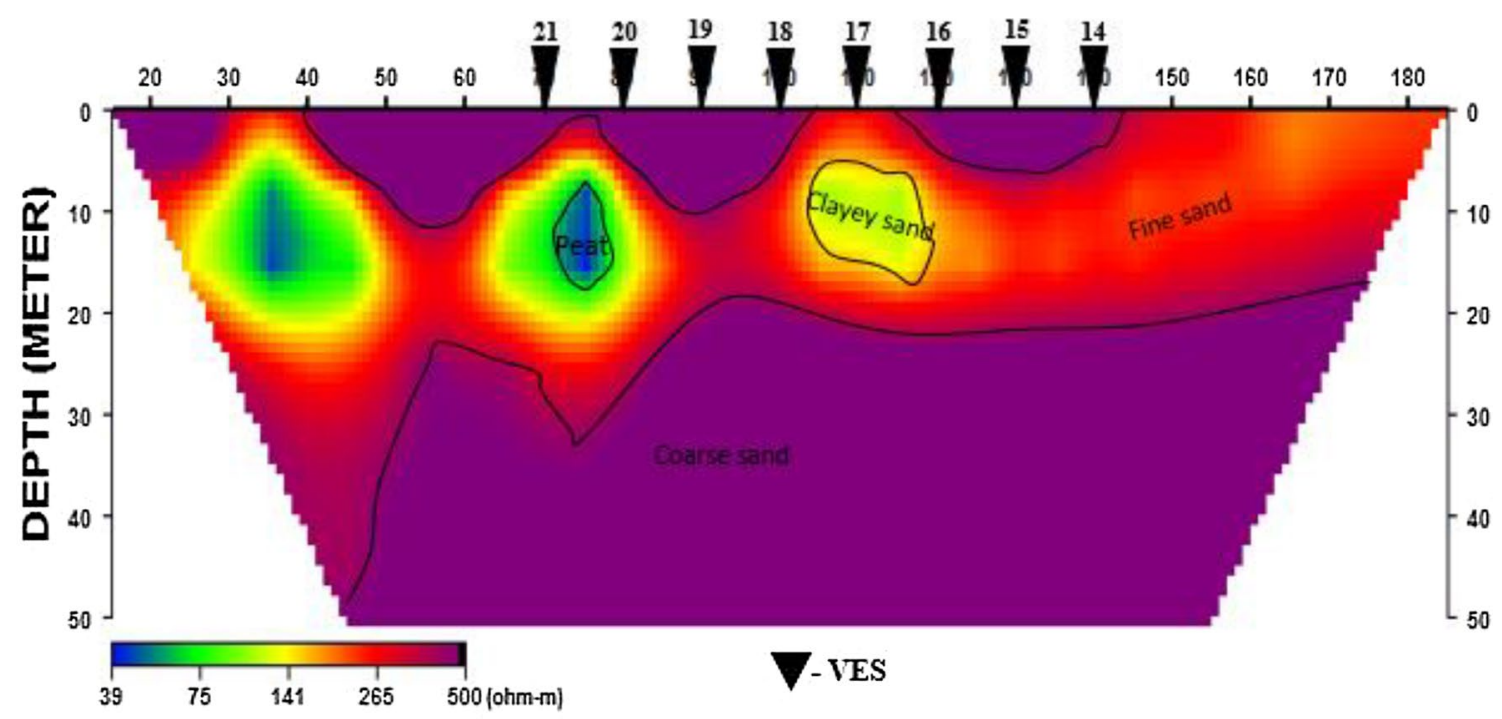

Fig. 14 Wenner 2-D resistivity structure along traverse three

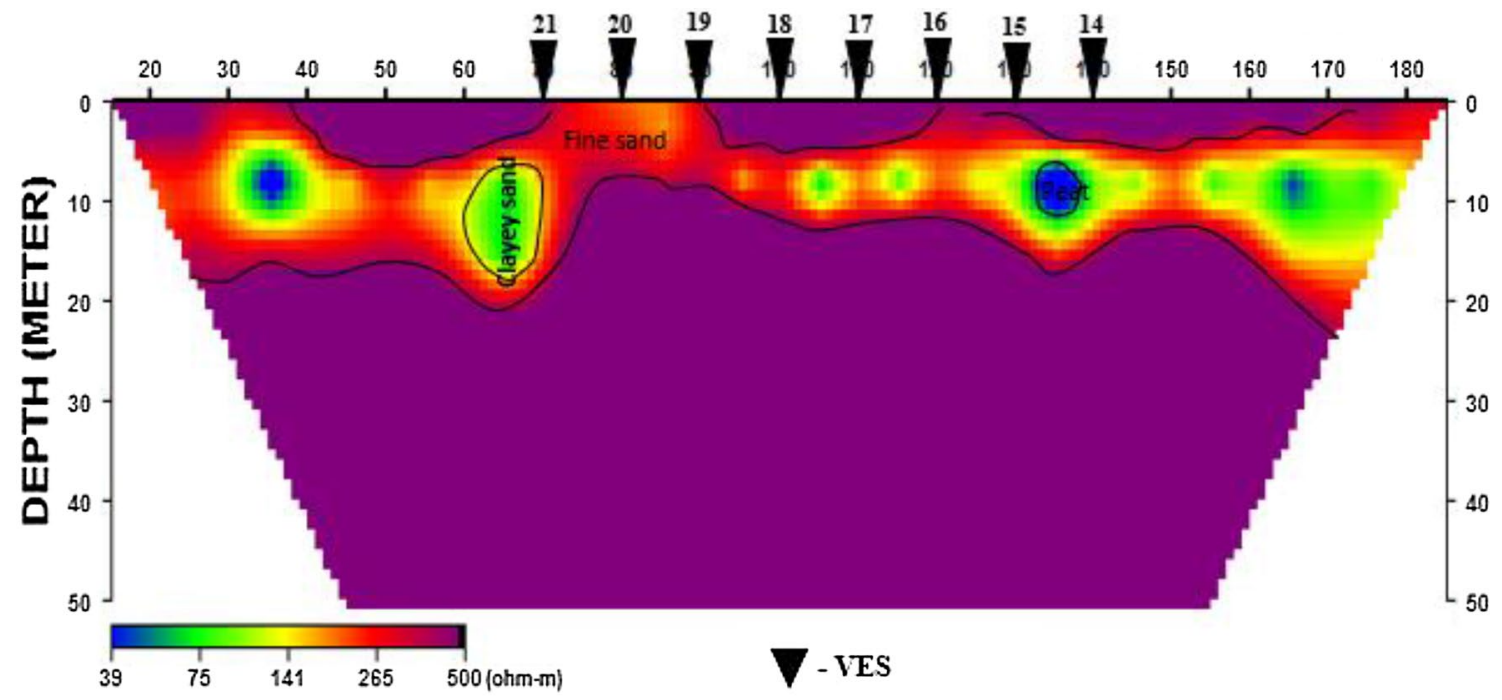

Fig. 15 Dipole-dipole 2-D resistivity structure along traverse three

are that: (1) foundations of engineering structures cannot be accommodated within the shallow sand layers up to a depth of about $0.6-0.9 \mathrm{~m}$. This is by virtue of the underlying sandy clay strata with resistivity ( $50 \Omega \mathrm{m}<\rho<140 \Omega \mathrm{m}$ ) which has moderate compressibility and at some locations underlain by highly compressible peat/clay $(\rho<50 \Omega \mathrm{m})$ and might cause differential settlement in the near future. Also due to the discontinuous nature of these underlying layers, there is high risk of the occurrence of subsidence and differential settlement which can impact severe damage to engineering structures. (2) Deep piling might be needed at majority of all the locations sand-filled with competent sand layers $(\rho>120 \Omega \mathrm{m})$ as the last layer which lies at deeper depth within 10-20 m. This study shows that detailed subsurface mapping is indispensable at reclaimed sites from wetlands, as a means of ascertaining the effectiveness of the sand-filling exercise and the degree of consolidation of the filled materials prior to commencement of construction works. This would 


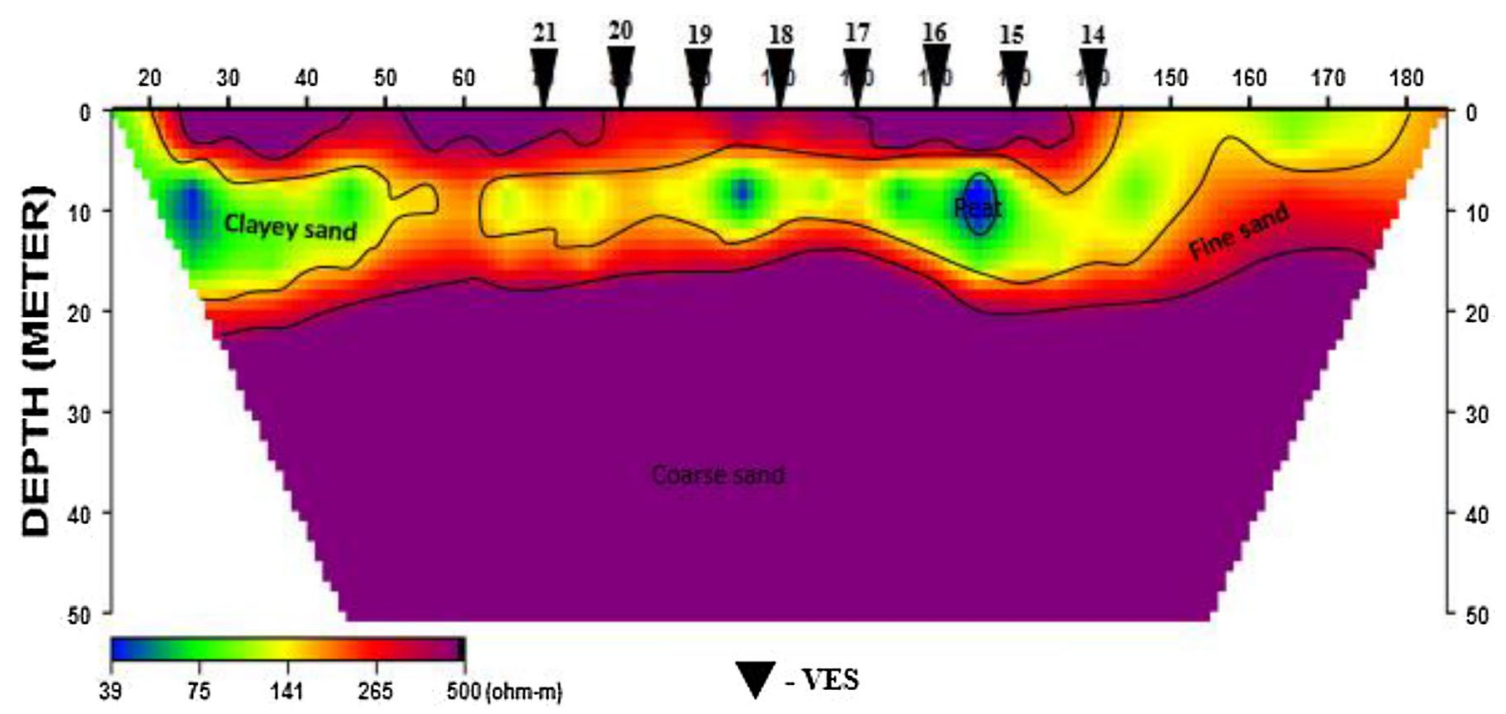

Fig. 16 Pole-dipole 2-D resistivity structure along traverse three

ultimately assist in locating regions of suitable and competent subsurface geological materials for erecting foundations of structures.

Acknowledgements The authors are very grateful to the Oniru chieftaincy family in Victoria Island, Lagos, Nigeria for the permission to carry out the geophysical field work at the study site. We also wish to acknowledge the contributions and participation of some undergraduate students in the data acquisition exercise.

\section{Compliance with ethical standards}

Conflict of interest The authors declare that they have no conflict of interest.

\section{References}

1. Akinbinu VA (2015) Delineation of saline water intrusion to safe-guide inland groundwater resources. Ocean Coast Manag 116:162-168. https://doi.org/10.1016/j.ocecoaman.2015.07.005

2. Adepelumi AA, Olorunfemi MO (2000) Engineering geological and geophysical investigation of the reclaimed Lekki Peninsula, Lagos, South West Nigeria. Bull Eng Geol Environ 58:125-132

3. Adepelmi AA, Ako BD, Ajayi TR, Afolabi O, Omotoso EJ (2009) Delineation of saltwater intrusion into the freshwater aquifer of Lekki Peninsula, Lagos, Nigeria. Environ Geol 56:927-933. https ://doi.org/10.1007/s00254-008-1194-3

4. Oyedele KF, Adesanya O (2010) Integrated geophysical and geotechnical methods in delineation of subsurface conditions at Magboro, Ogun State, Nigeria. J Environ Sci Technol 10(2):16-22

5. Oyedele KF, Oladele S, Okoh C (2015) Assessment of subsurface conditions in a coastal area of Lagos using geophysical methods. Niger J Technol Dev 12(2):36-41

6. Oladele S, Oyedele KF, Dinyo MO (2015) Pre-construction geoelectrical and geotechnical assessment of an engineering site at Alapere/Agboyi, Lagos, Nigeria. Ife J Sci 17(3):543-552
7. Jorat ME, Kreiter S, Mörz T, Moon V, de Lange W (2013) Strength and compressibility characteristics of peat stabilized with sand columns. Geomech Eng 5(6):575-594. https://doi.org/10.12989 /gae.2013.5.6.575

8. Elawadi E, El-Qady G, Nigm A, Shaaban F, Ushijima K (2006) Integrated geophysical survey for site investigation at a new dwelling area, Egypt. J Environ Eng Geophys 11(4):249-259. https:// doi.org/10.2113/JEEG11.4.249

9. Sudha K, Israil M, Mittal S, Rai J (2009) Soil characterization using electrical resistivity tomography and geotechnical investigations. J Appl Geophys 67:74-79. https://doi. org/10.1016/j.jappgeo.2008.09.012

10. Arulrajan A, Bo MW, Nikraz H (2004) Field instrumentation monitoring of land reclamation projects on marine clay formations. Aust Geomech 39(1):69-77. https://doi.org/10.1680/ geng.2009.162.1.33

11. Bo MW, Arulrajan A (2013) Planning and implementation of a Mega Geotechnical Engineering Project in Singapore. In: International conference on case histories in geotechnical engineering paper, vol 36

12. Jiao JJ (2009) Modification of regional groundwater regions by land reclamation. Hong Kong Geol 6:29-36

13. Mzila N, Shuy EB (2003) Studies on groundwater salinity distribution in a coastal reclaimed land in Singapore. In: International conference on estuaries and coasts 9-11 Nov Hangzhou China

14. Guo H, Jiao JJ (2007) Impact of coastal land reclamation on ground water level and the sea water interface Groundwater 45(3):362-367

15. Burak S, Kucukakca E (2015) Impact of land reclamation on the coastal areas in Istanbul. In: Geophysical research abstracts, EGU2015-4881, vol 17

16. Gatto M (2015) Does reclamation pay? Assessing the socioeconomic effects of reclamation projects Terra et Aqua No. 38:25-35

17. Dobrin MB, Savit CH (1988) Introduction to geophysical prospecting, 4th edn. McGraw-Hill, New York

18. Telford WM, Geldart LP, Sheriff RE, Keys DA (1990) Applied geophysics. Cambridge University Press, Cambridge

19. Reynolds JM (1998) An introduction to applied and environmental geophysics, 2nd edn. Wiley, Hoboken 
20. TerraDat Geophysical Innovations (2005) The use of shallow geophysical surveys applied to engineering and environmental ground investigations. TerraDat UK Ltd., Cardiff

21. El-Qady G, Metawaly M, El-Galadi A, Ushijima K (2005) Evaluation of peat formation using geoelectrical methods at Nile Delta, Egypt. Mem Fac Eng Kyushu Univ 65(1):1-13

22. Cosenza P, Marmet E, Rejiba F, Cui YJ, Tabbagh A, Charlery $Y$ (2006) Correlations between geotechnical and electrical data: a case study at Garchy in France. J Appl Geophys 60:165-178. https://doi.org/10.1016/j.jappgeo.2006.02.003

23. Soupios PM, Georgakopoulos P, Papadopoulos N, Saltas V, Andreadakis A, Vallainatos F, Sarris A, Makris JP (2007) Use of engineering geophysics to investigate a site for a building foundation. J Geophys Eng 4:94-103. https://doi. org/10.1088/1742-2132/4/1/011

24. Rucker DF, Noonman GE (2013) Using marine resistivity to map geotechnical properties: a case study in support of dredging the Panama Canal. Near Surf Geophys 11:625-637. https://doi. org/10.3997/1873-0604.2012017

25. Maślakowska M, Kowalczyk S, Mieszkowski R, Józefiak K (2014) Using electrical resistivity tomography (ERT) as a tool in geotechnical investigation of substrate of a highway. Studia Quaternaria 31(2):83-89. https://doi.org/10.2478/squa-2014-0008

26. Kowalczyk S, Zawrzykraj P, Mieszkowski R (2015) Application of electrical resistivity tomography in assessing complex soil conditions. Geol Q 59(2):367-372. https://doi.org/10.7306/gp.1172

27. Adewoyin OO, Joshua EO, Akinyemi ML (2017) Application of geophysical and geotechnical methods to determine the geotechnical characterization of a reclaimed land. Search and Discovery Article \#70255

28. Koda E, Tkaczyk A, Lech M, Osiński P (2017) Application of electrical resistivity data sets for the evaluation of the pollution concentration level within landfill subsoil. Appl Sci 7(3):262. https:// doi.org/10.3390/app7030262

29. Kowalczyk S, Zawrzykraj P, Maślakowska M (2017) Application of the electrical resistivity method in assessing soil for the foundation of bridge structures: a case study from the Warsaw environs, Poland. Acta Geodyn Geomater 14(2):221-234. https ://doi.org/10.13168/AGG.2017.0005

30. Kowalczyk S, Zukowska KA, Mendecki MJ, Lukasiak D (2017) Application of electrical resistivity imaging (ERI) for the assessment of peat properties: a case study of the Calowanie Fen, Central Poland. Acta Geophys 65(1):223-235. https://doi. org/10.1007/s11600-017-0018-9

31. Ronczka M, Hellman K, Günther T, Wisén R, Dahlin T (2017) Electric resistivity and seismic refraction tomography: a challenging joint underwater survey at Äspö Hard Rock Laboratory. Solid Earth 8:671-682. https://doi.org/10.5194/ se-8-671-2017

32. Massarch KR (2000) Geophysical methods for geotechnical, geoenvironmental and geo-dynamic site characterization. In: 3rd international workshop on the applications of geophysics to rock and soil engineering, 18 Nov 2000 Melbourne, Australia

33. Neil A, Neil C, Rick H, Phil S (2008) Geophysical methods commonly employed for geotechnical site characterization. Transportation research circular, No. E-C130:44

34. Olorunfemi MO, Meshida EA (1987) Engineering geophysics and its application in engineering site investigations (Case study from llelfe area). Niger Eng 22:57-66

35. Gautam PK, Sastry RG, Mondal SK (2007) The utility of multielectrode resistivity data in geotechnical investigations: a case study. In: 20th symposium on the application of geophysics to engineering and environmental problems (SAGEEP), pp 731-737

36. Adepelumi AA, Fayemi O (2012) Joint application of ground penetrating radar and electrical resistivity measurements for characterization of subsurface stratigraphy in Southwestern Nigeria. J Geophys Eng 9:397-412. https://doi. org/10.1088/1742-2132/9/4/397

37. Atakpo EA, Akpoborie A, Ayolabi EA (2011) Evaluation of Aquifer contamination using 2D geoelectric imaging at Ikeja, Lagos, Nigeria. J Environ Hydrol 19:1-7

38. Ayolabi EA, Enoh IJE, Folorunso AF (2013) Engineering site characterisation using 2-D and 3-D electrical resistivity tomography. Earth Sci Res 2(1):133-142

39. Sastry RG, Gautam PK (2013) Geotechnical site characterization through geoelectrics. In: 10th biennial international conference and exposition, 23-25 Nov 2013, Kochi, Kerala, India

40. Vondráčková T, Musílek J, Kais L (2015) The issue of soft rocks causing problems in foundation engineering. Proc Earth Planet Sci 15:54-59. https://doi.org/10.1016/j.proeps.2015.08.015

41. Ayolabi EA, Folorunsho AF, Jegede OE (2012) An application of $2 \mathrm{D}$ electrical resistivity tomography in geotechnical investigations of foundation defects: a case study. J Geol Min Res 3(12):142-151

42. Olorode DO, Olatinsu OB, Ugwoke EE (2012) Site investigation using a combination of electrical resistivity technique and CPT-A case study of a coastal area of Lagos, Nigeria. Eur J Sci Res 81(3):344-356

43. Adeoti L, Kehinde I, Adegbola RB, Sovi ST (2009) Foundation investigation using electrical resistivity method: a case study of Iponri, Lagos State, Nigeria. J Eng Res 14(1):50-57

44. Salami BM, Falebita DE, Fatoba JO, Ajala MO (2012) Integrated geophysical and geotechnical investigation of a bridge site: a case study of a swamp/creek environment in south east Lagos, Nigeria. Ife J Sci 14(1):79-82

45. Longe EO, Malamo S, Olorunniwo MA (1987) Hydrogeology of Lagos metropolis. J Afr Earth Sci 6(2):163-174

46. van Bentum KM (2012) The Lagos coast: investigation of the long-term morphological impact of the Eko Atlantic City project. M.Sc. thesis, Delft University of Technology, Netherland

47. Africa Business Initiative (2013) Investment climate update: techno cities U.S. Chamber of Commerce, IInternational affairs. $4(1): 4$

48. Adebayo AK (2014) Emerging 'New cities' in Africa and sociospatial inequality: a case study of the Eko Atlantic City project in Lagos, Nigeria. M.Sc. thesis, University of Amsterdam, Netherland

49. Jones HA, Hockey RD (1964) The geology of part of southwestern Nigeria. Geol Surv Niger Bull 31:1-101

50. Short KC, Stauble AJ (1969) Outline of geology of the Niger Delta. Bull Am Assoc Petrol Geol 54:761-779

51. Onyeagocha AC (1980) Petrography and depositional environment of the Benin Formation. J Min Geol 17:147-151

52. Pugh JC (1954) A classification of the Nigerian coastline. J W Afr Sci 1:3-12

53. Hill MB, Webb JF (1958) The topography and physical features of Lagos Harbour. Philos Trans R Soc Ser B 241:319-333

54. Adegoke OS, Jeje LK, Durotoye B, Adeleye DR, Ebukanson EE (1980) The geomorphology and aspects of sedimentology of region of region of western Nigeria. J Min Geol 17:217-223

55. Orellana E, Mooney HM (1966) Master tables and curves for vertical electrical soundings over layered structures. Interciencia, Madrid

56. Bhattacharya PK, Patra HP (1968) Direct current geoelectric sounding: principles and interpretation. Elsevier, Amsterdam, p $135 p$

57. Vander-Velpen BPA, Sporry RJ (1993) RESIST: a computer program to process resistivity sounding data on PC compatibles. Comput Geosci 19(5):691-703 
58. Vander-Velpen BPA (2004) WinRESIST version 1.0 resistivity depth sounding interpretation software. M.Sc. Research Project, ITC, Delft, Netherland

59. Ward SH (1990) Resistivity and induced polarization methods. In: Ward SH (ed) Geotechnical and environmental geophysics, vol 1. Society of Exploration Geophysicists, Tulsa

60. Kearey P, Brooks M (1991) An introduction to geophysical exploration. Wiley, Hoboken

61. Griffiths DH, Turnbull J, Olayinka Al (1990) Two dimensional resistivity mapping with a computer-controlled array. First Break 8:121-129

62. Griffiths DH, Barker RD (1993) Two dimensional resistivity imaging and modelling in areas of complex geology. J Appl Geophys 29:211-226
63. Dahlin T (1996) 2D resistivity surveying for environmental and engineering applications. First Break 14:275-283

64. Dahlin T, Zhou B (2004) A numerical comparison of 2D resistivity imaging with 10 electrode arrays. Geophys Prospect 52:379-398

65. KIGAM (2001) DIPRO $^{\mathrm{TM}}$ version 4.01 (2001) Processing and interpretation software for electrical resistivity data. Korea Institute of Geoscience and Mineral Resources (KIGAM), Daejeon, South Korea

66. Bowles JE (1984) Physical and geotechnical properties of soils, 2nd edn. McGraw-Hill, Inc., London

67. Das B (1994) Principles of geotechnical engineering. PWS-Kent Publishing Company, Boston

68. AASHTO (2002) Standard specifications for highway bridges, 17th edn. AASHTO, Washington, DC 